\title{
ERRATUM
}

\section{Erratum for Lamichhane et al., Lack of tRNA Modification Isopentenyl-A37 Alters mRNA Decoding and Causes Metabolic Deficiencies in Fission Yeast}

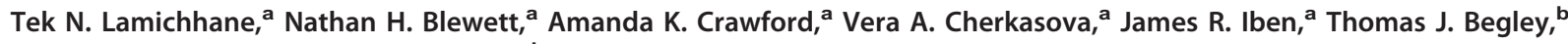
Philip J. Farabaugh, ${ }^{\mathrm{c}}$ Richard J. Maraia ${ }^{\mathrm{a}, \mathrm{d}}$

Intramural Research Program, NICHD, NIH, Bethesda, Maryland, USA'; College of Nanoscale Science and Engineering, University at Albany, Albany, New York, USA

Department of Biological Sciences, University of Maryland Baltimore County, Baltimore, Maryland, USA c; Commissioned Corps, U.S. Public Health Service, Washington, DC, USA

Volume 33, no. 15, p. 2918-2929, 2013. Page 2923, Fig. 3 legend, line 2: “ $\mathrm{gg} / \mathrm{ml} ”$ should read “ng/ml.” 